\title{
Machining FEM model of long fiber composites for aeronautical components
}

\author{
Carlos Santiuste $^{\mathrm{a}}$, Xavier Soldani ${ }^{\mathrm{b}}$, Maria Henar Miguélez ${ }^{\mathrm{b}, *}$ \\ ${ }^{a}$ Department of Continuum Mechanics and Structural Analysis, University Carlos III of Madrid, Avda. de la Universidad 30, 28911 Leganés, Madrid, Spain \\ ${ }^{\mathrm{b}}$ Department of Mechanical Engineering, University Carlos III of Madrid Avda. de la Universidad 30, 28911 Leganés, Madrid, Spain
}

Keywords:

Machining induced damage

Aeronautical components

Orthogonal cutting

LFRP composite
This work is focused on the study of orthogonal cutting of long fiber composites. A model based in finite element was developed. The mechanisms of chip formation of Glass and Carbon Fiber Reinforced Polymer (FRP) composites were analyzed. Significant differences were observed when comparing machining induced damage predicted with the model for both materials. While damage extended widely ahead the interface and beneath the tool tip in the case of GFRP, damage was located in a much smaller zone in the case CFRP. The fiber orientation influences both the mechanism of chip formation and the induced subsurface damage.

\section{Introduction}

Long Fiber Reinforced Polymer (LFRP) composites have been extensively used in structural components. Their attractive properties, fatigue and corrosion resistance combined with lightweight, high specific stiffness and strength, made this family of materials suitable for a wide range of applications in aeronautical, automotive, marine and sporting industries.

The problems associated with precision and efficiency in cutting LFRP composites have become important issues in the manufacturing field. Although the components are usually made to the final size of the desired product, machining processes, mainly trimming, milling and drilling are needed to achieve dimensional tolerance and assembly requirements. LFRP composites are considered difficult to cut materials due to the presence of hard fibers, being especially vulnerable to the generation of damage, mainly delamination, fiber pull-out and matrix thermal degradation [1].

Experimental investigation of machining of low machinability materials such as LFRP composites, is time consuming and expensive. Moreover health hazards associated to fibers inhalation and contact with skin, reduces the possibility to carry out extensive experimental research on LFRP composites machining. On the other hand the shape of the composite, usually thin walled, also complicates the execution of the tests, commonly performed at low cutting speeds achieved after complex positioning process in machine-tool, see for instance the works [2-4] focused on orthogonal cutting of Glass and Carbon FRP composites. These authors carried out significant experimental works on orthogonal cutting of GFRP. They studied the effect of fiber orientation, depth of cut,

\footnotetext{
* Corresponding author. Tel.: +349162494 02; fax: +34 916249430 .

E-mail address: mhmiguel@ing.uc3m.es (M.H. Miguélez).
}

rake angle and cutting edge radius. Experimental results obtained in these works have been widely used to validate numerical models in scientific literature. The numerical model presented in this work was validated with experimental data from Ref. [3].

On the other hand, Finite Element (FE) is a powerful method offering the possibility to complete experimental studies, avoiding technical problems and elevated cost. Other advantage is the possibility to uncouple influencing parameters in problems depending on a large number of variables such as machining processes [5].

The present work is focused on the numerical modelling of orthogonal cutting of LFRP composites. Industrial machining processes involves oblique cutting, however orthogonal cutting is commonly the objective of simulations in machining numerical studies, due to its simplicity and utility to obtain information about difficult to measure variables [5].

Comparing to the large number of scientific works dealing with metal cutting, a limited amount of technical literature exists on FE analysis of orthogonal cutting of LFRP composites. Mainly macro and micro mechanical models were developed, although also combined micro-macro approach to the orthogonal cutting process were presented in $[6,7]$, obtaining good prediction of cutting forces.

In a recent work [8] a two-phase micro mechanical model of both glass and carbon fiber reinforced polymer composite was developed. Micro mechanical modelling reproduces the fiber, the surrounding matrix and the complex fiber-matrix interface. Decohesion phenomena was predicted and strong influence of the fiber orientation on the failure mechanisms was found.

Macro-mechanical approaches modelled the composite as an anisotropic homogeneous material. In general unidirectional fiber orientation was assumed in two dimensional approaches. Arola and Ramulu [9] presented the first study of orthogonal cutting of 
unidirectional composites based on finite element. Ramesh et al. [10] studied the influence of orientation for four different FRPs. Failure mechanism based on fiber-matrix cracking was implemented, obtaining that the load needed to induce failure was dependent on the fiber orientation. Mahdi and Zhang [11,12] used both $2 \mathrm{D}$ and $3 \mathrm{D}$ approaches to simulate composite cutting. 2D analysis reproduced an equivalent homogeneous material predicting cutting forces of FRP as a relation to the fiber orientation. 3D approach simulated a composite cell based on different constituents (fiber and matrix) perfectly bonded. Arola et al. [13] focused on the influence of tool geometry on cutting forces and subsurface damage for orthogonal machining of unidirectional FRPs. It is generally shown in these studies that good approximation to experimental cutting forces has been obtained while the thrust forces were poorly predicted. The same problem has been observed in numerical simulations of metal cutting due to the difficulty to reproduce the complex interaction between tool and workpiece [5].

Structural applications for aeronautical components need excellent mechanical properties usually achieved with Carbon FRP composites. The enhanced mechanical properties characterizing the carbon fiber influences the chip generation and also the subsurface damage.

Main objective of this paper is the numerical analysis of orthogonal cutting of CFRP composites. A macro-mechanical model was developed allowing the simulation of the initiation and complete chip during the evolution of the cutting process. In general, numerical models in literature are based in a quasi-static analysis, focusing on the initial instant of cutting process. The study of machined surface integrity requires the simulation of a significant cutting length. In this paper a dynamic approach to chip removal was performed using explicit integration scheme in a FE code.
Machinability and surface integrity of long fiber reinforced composites are mainly governed by the fiber-orientation relative to the cutting direction [4]. The subsurface damage induced on CFRP was analyzed for different fiber orientation and it is compared with results obtained when machining GFRP. Numerical model was validated with experimental data obtained from scientific literature for GFRP.

\section{Numerical modelling}

\subsection{Geometry, meshing and analysis}

A plane stress model was developed using the commercial Finite Element code ABAQUS/Explicit. A dynamic explicit analysis was developed, with plane stress, quadrilateral, linearly interpolated, elements, with reduced integration and automatic hourglass control (CP4SR in ABAQUS/Explicit notation [14]).

Geometry and boundary conditions of the numerical model are shown in Fig. 1. The values of cutting parameters and tool

Table 1

Characteristics of materials used in simulations [3,19].

\begin{tabular}{lll}
\hline Mechanical properties & Glass FRP & Carbon FRP \\
\hline Longitudinal modulus, $E_{1}(\mathrm{GPa})$ & 48 & 126 \\
Transverse modulus, $E_{2}(\mathrm{GPa})$ & 12 & 11 \\
In-Plane shear modulus, $G_{12}(\mathrm{GPa})$ & 6 & 6.6 \\
Major Poisson's ratio, $v_{12}$ & 0.28 & 0.28 \\
Longitudinal tensile strength, $X_{T}(\mathrm{MPa})$ & 1200 & 1950 \\
Longitudinal compressive strength, $X_{C}(\mathrm{MPa})$ & 800 & 1480 \\
Transverse tensile strength, $Y_{T}(\mathrm{MPa})$ & 59 & 48 \\
Transverse compressive strength, $Y_{C}(\mathrm{MPa})$ & 128 & 200 \\
Shear strength, $S(\mathrm{MPa})$ & 25 & 79 \\
\hline
\end{tabular}

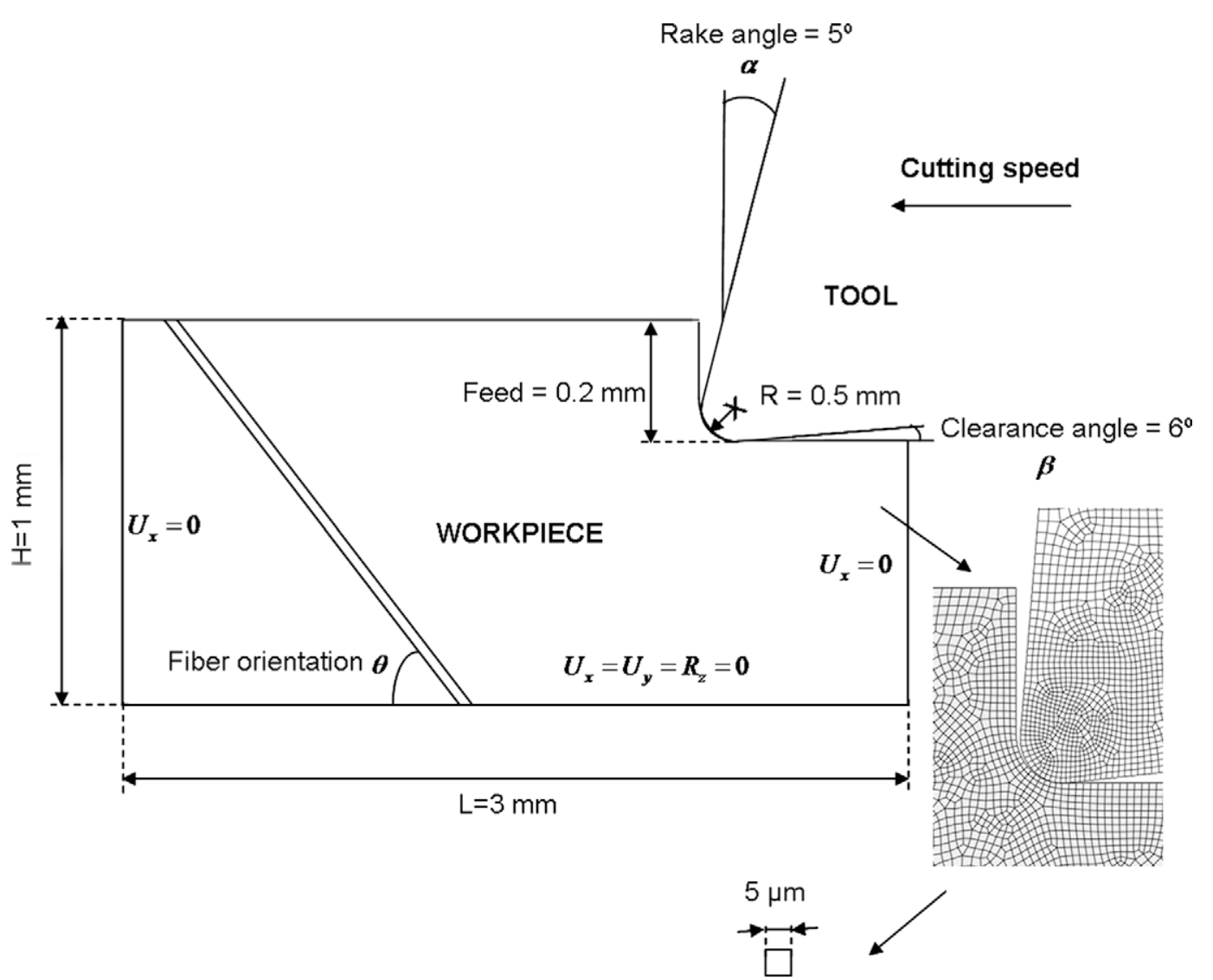

Fig. 1. Model geometry, boundary conditions and detail of mesh around the tool tip. 
geometry (depth of cut, cutting speed, rake angle, clearance angle, and edge radius) were coherently defined with those used in [3] in order to validate predicted numerical results. The aim of the model is to analyze not only the chip initiation phenomena, also the evolution of cutting process. Thus a cutting length equal to $2 \mathrm{~mm}$ was considered, enough to reach steady state conditions during cutting process. In metal cutting, larger values of cutting length are needed to reach thermal steady state conditions [15], while thermal issues are not accounted when modelling composite cutting.

Conditional stability is the only concern about explicit integration, requiring very small time step. This time is in the order of the time required by a dilatational wave to cross the smallest element, typically around $10^{-10}-10^{-9} \mathrm{~s}$, leading to large calculation time. Thus the element size should be defined under the point of view of both accuracy and time efficiency of the calculation. The mesh of workpiece (see Fig. 1) was refined in the zone surrounding the tool tip in order to model accurately the evolution of damage associated to chip initiation and evolution. The medium element size at this zone was $5 \mu \mathrm{m}$.

\subsection{Materials and damage modelling}

The model configuration shown in Fig. 1 was applied to the cutting simulation of both Glass and Carbon FRP composites. Both

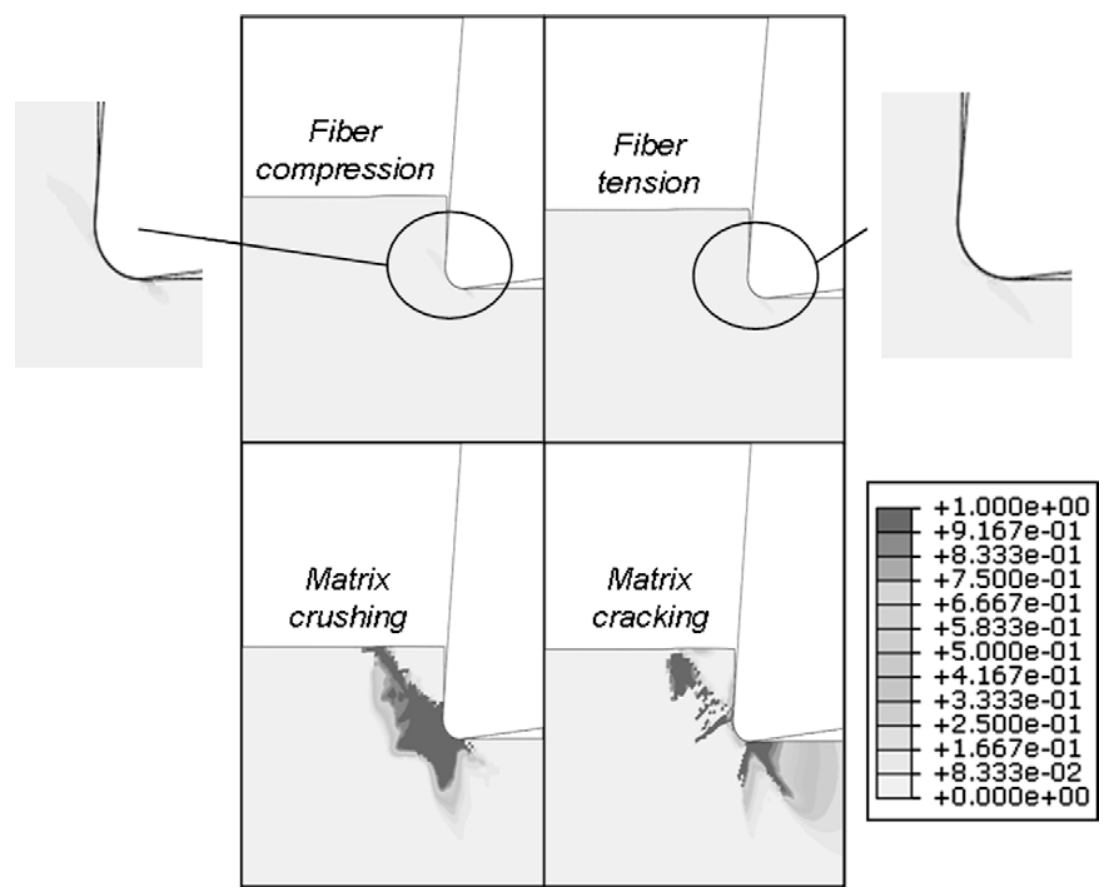

Fig. 2. Damage modes in GPRF showing negligible fiber damage (fiber orientation $45^{\circ}$, cutting time $1.2 \mathrm{~ms}$ ).
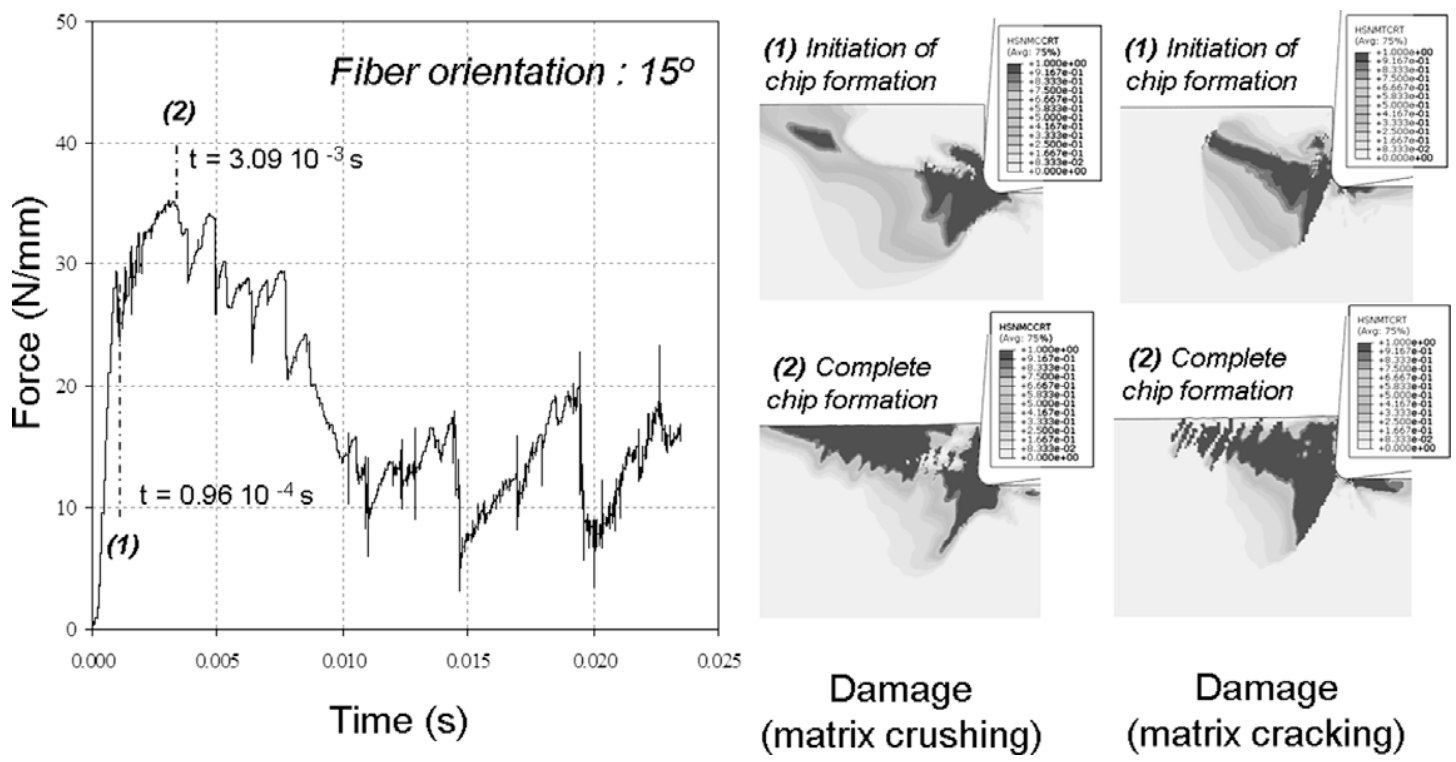

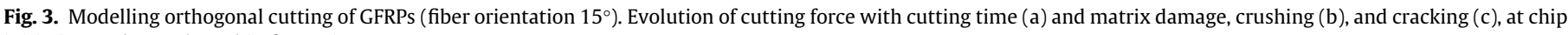
initiation and complete chip formation. 
materials were modelled with an elastic behaviour up to failure, taking into account the anisotropy of the material. The tool was assumed to be rigid.

The damage initiation criteria for fiber reinforced composites are based on Hashin's theory $[16,17]$. The composite failure criteria proposed by Hashin [16] includes four failure modes: fiber tensile failure, fiber compressive failure, matrix cracking, and matrix crushing (Eqs. (1)-(4))

- Fiber tension $\left(\sigma_{11}>0\right)$ :

$d_{f}^{t}=\left(\frac{\sigma_{11}}{X^{T}}\right)^{2}+\alpha\left(\frac{\tau_{12}}{S^{L}}\right)^{2} \leqslant 1$

- Fiber compression $\left(\sigma_{11}<0\right)$ :

$d_{f}^{c}=\left(\frac{\sigma_{11}}{X^{c}}\right)^{2} \leqslant 1$

- Matrix cracking $\left(\sigma_{22}>0\right)$ :

$d_{m}^{t}=\left(\frac{\sigma_{22}}{Y^{T}}\right)^{2}+\left(\frac{\tau_{12}}{S^{L}}\right)^{2} \leqslant 1$

- Matrix crushing $\left(\sigma_{22}<0\right)$ :

$d_{m}^{c}=\left(\frac{\sigma_{22}}{2 S^{T}}\right)^{2}+\left[\left(\frac{Y^{C}}{2 S^{T}}\right)^{2}-1\right] \frac{\sigma_{22}}{Y^{C}}+\left(\frac{\tau_{12}}{S^{L}}\right)^{2} \leqslant 1$

where $\sigma_{11}$ denotes the stress in fiber direction, $\sigma_{22}$ the stress in transverse direction, and $\tau_{12}$ the in-plane shear stress.

Under a given load, the stresses at each integration point in the workpiece were computed. Then, the failure modes were evaluated, if any failure criterion reached the unity, the elastic properties at that element had to be degraded according to the mode of failure. Fiber failure, produced degradation of both longitudinal and shear modulus, and matrix failure produces degradation of transverse and shear modulus.

Damage initiation refers to the onset of degradation at a material point and is used to predict rupture and subsequent deletion of the damaged element.

The degradation of material properties was modelled decreasing the level of the properties related with stiffness equal to zero. However the zero value was not stated immediately after the initiation of damage. It should be taken into consideration the energy necessary to break the element completely. The statement of this level of energy is crucial to simulate the material behaviour: when low level of energy is implemented the element is eroded just after the damage onset, while high level of energy allows high deformation of the element before total breakage. Thus it is possible to distinguish between ductile composite materials, showing progressive failure; and brittle composite materials, presenting sudden breakage, not only in machining processes, also when experiencing other dynamic loadings. In general, the GFRPs could be included in the former category and CFRPs in the second [18].

Glass FRP behaviour is modelled from data in [3]. The carbon fiber reinforced material was considered to be made of AS4 carbon fiber and 3501-6 epoxy matrix. This material was selected because of its excellent specific mechanical properties. The mechanical properties were obtained from the study of this material in an international exercise (World-Wide Failure Exercise [19,20]), comparing different failure criteria for composite materials. Materials parameters are summarized in Table 1.

Different fiber orientations (see Fig. 1 ), $\theta$ equal to $15^{\circ}, 30^{\circ}, 45^{\circ}$, $60^{\circ}, 75^{\circ}$ and $90^{\circ}$, were considered in order to analyze the influence of this parameter on the cutting force and machining induced damage.

\subsection{Contact modelling}

Interaction between workpiece and tool was modelled by using surface - node surface contact available in ABAQUS/Explicit [14]. Friction at the interface is one of the hardest phenomena to simulate in machining. In the present work, a constant coefficient of friction equal to 0.5 at the tool/workpiece interface was assumed [21]. Although it is the simplest formulation, it has been widely used in numerical simulation of machining both for metallic and composite workpiece [15,21].

\section{Results and discussion}

Numerical results concerning orthogonal cutting of Glass FRPs, experimental validation and the application of the model to the simulation of orthogonal cutting of Carbon FRPs are presented in the following paragraphs. Chip initiation and complete chip formation were analyzed.
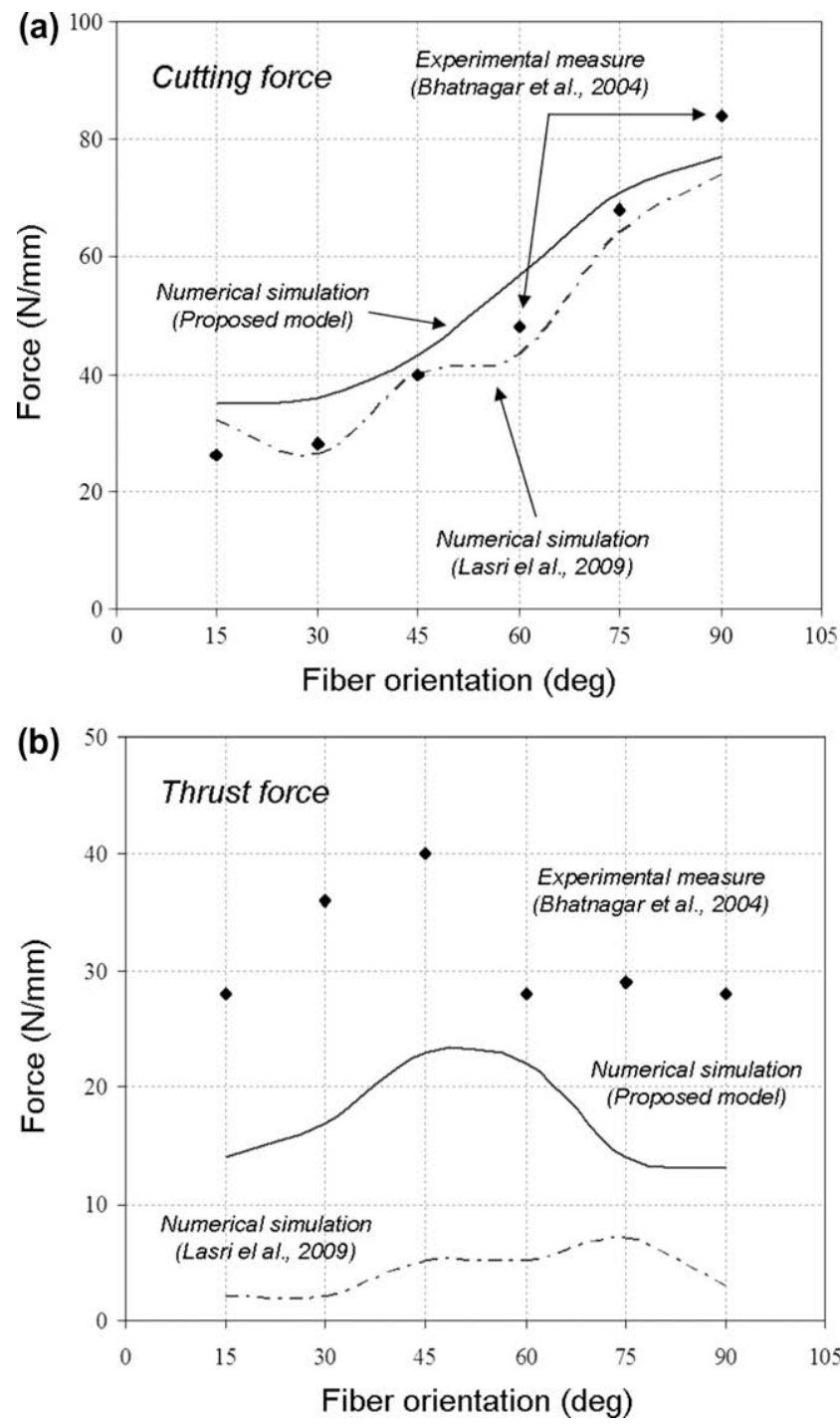

Fig. 4. Cutting (a) and thrust (b) forces versus fiber orientation. Comparison between numerical data in the present work, numerical data in [21] and experimental data in [3]. 

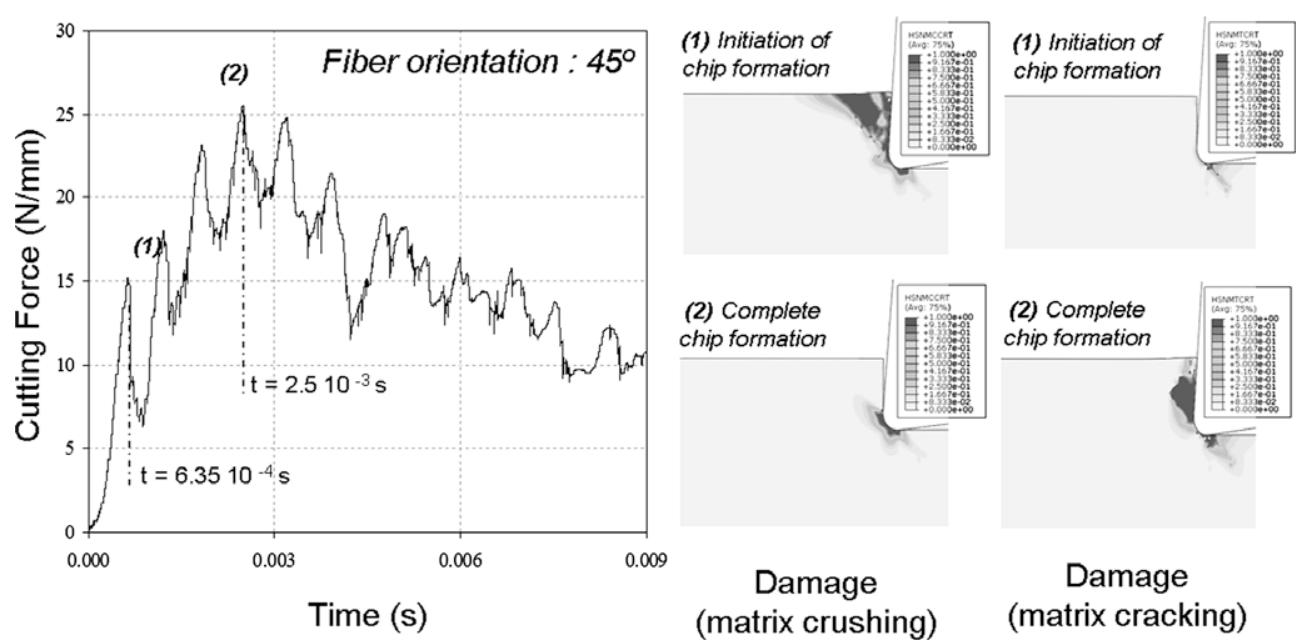

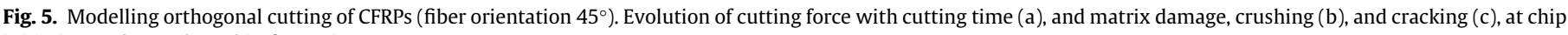
initiation and complete chip formation.

\subsection{Modelling orthogonal cutting of glass FRPs and experimental validation of the model}

Understanding of chip evolution process (initiation and complete chip formation) needed the analysis of all composite damage modes. As can be deduced from Fig. 2 (orientation $45^{\circ}$, cutting time $1.2 \mathrm{~ms}$ ) while fiber failure modes are almost negligible, matrix experienced both compression and tensile damage. The matrix presented lower failure stress, being matrix crushing (compressive) more extended than matrix cracking in the zone ahead and under the tool tip. Beneath the machined surface the matrix cracking (tensile) mode is more significant and the penetration is deeper than crashing damage.

Cutting force obtained in the case of fiber orientation $15^{\circ}$ is shown in Fig. 3a. First zone of the curve up to cutting time around $1 \mathrm{~ms}$ corresponds with chip initiation. Damage appeared ahead and beneath the tool chip, as is shown in the matrix damage fields in Fig. 3b. The evolution of damage with cutting time (the tool penetrating the workpiece) leaded to complete chip formation at cutting time around $3 \mathrm{~ms}$, reaching at this moment the maximum value of the force. From this time the cutting force decreased due to the extended damage, and the chip was removed. It is important to remark that the maximum peak value of the cutting force is assumed to be the "cutting force" in most works dealing with simulation of composite cutting. However this value is the maximum force needed to generate the first chip from intact material. Second and following chips were generated in previously damaged composite, since the damage was extended in the zone of uncut chip, in front of the tool, thus the cutting force was not as elevated as the value of the first peak. In metal cutting it is normally admitted as cutting force the stabilized value once steady state conditions are reached. Since quasi-static analysis has been commonly performed in composite cutting studies in literature, stabilized value of the force is not available. Fig. 3a shows the evolution of cutting force showing periodicity as subsequent chips are formed. This profile reminds those obtained when cutting thermal resistant alloys forming segmented chips, such as Ti alloys.

The maximum peak value of both cutting force and thrust force at the cutting time corresponding to complete chip formation, were obtained for all fiber orientations. Numerical results obtained in the present work were compared with experimental and numerical data presented respectively in $[3,21]$ (see Fig. 4a and b). Maximum values of cutting force obtained with the model proposed in this work, showed good accuracy when compared with both numerical and experimental results in scientific literature. However, thrust force presented significant differences between predicted and experimental results. It should be noted the difficulty to accurately model the thrust force, even in the well-known case of metallic workpiece. The model proposed in this work improved the accuracy of the thrust force prediction presented in [21]. This fact could be related with the characteristics of the normal and tangential contact imposed at the interface workpiece-tool.

On the other hand comparison between matrix damage fields in Figs. 2 and $3 \mathrm{~b}$ demonstrated the influence of fiber orientation on induced damage and chip formation mechanism. The size of affected zone in front of the tool was increased when the fiber orientation diminished. In fact, the inclination of the primary zone (considering this zone to be a narrow line between undamaged and damaged material in front of the tool) was strongly dependent on fiber angle and it seems from Figs. 2 and $3 \mathrm{~b}$ to be oriented in the same direction of the fiber.

\subsection{Modelling orthogonal cutting of carbon FRPS}

The numerical model was applied to analyze orthogonal cutting of Carbon FRPs. The prevalent damage modes were also found to be matrix crushing and cracking.

Cutting force obtained in the case of fiber orientation equal to $45^{\circ}$ is shown in Fig. 5. Initiation of chip corresponds with cutting time $0.63 \mathrm{~ms}$, at this moment damage appeared in a small zone surrounding the tool tip. The matrix damage was extended with the evolution of cutting time mainly ahead the primary zone with an inclination almost equal to fiber angle. Matrix cracking mode affected a smaller zone than crushing mode. The maximum value of cutting force was reached at $2.5 \mathrm{~ms}$, corresponding with completely formed chip and segmentation.

Complete chip formation is compared for GFRPs and CFRP in Fig. 6 for the same fiber orientation equal to $45^{\circ}$. In the case on GFRPs the damaged zone was widely extended both beneath and in front of the tool tip. However simulations of CFRP showed that the affected zone was much smaller. The damage was restricted to the vicinity of chip. The damage was initiated close to the tool tip, evolved towards the region located between the primary zone and the interface and finally most of the damaged zone is removed with the chip segmentation. This behaviour observed with orientation equal to $45^{\circ}$ is an important advantage for CFRPs materials commonly used in high responsibility applications. 

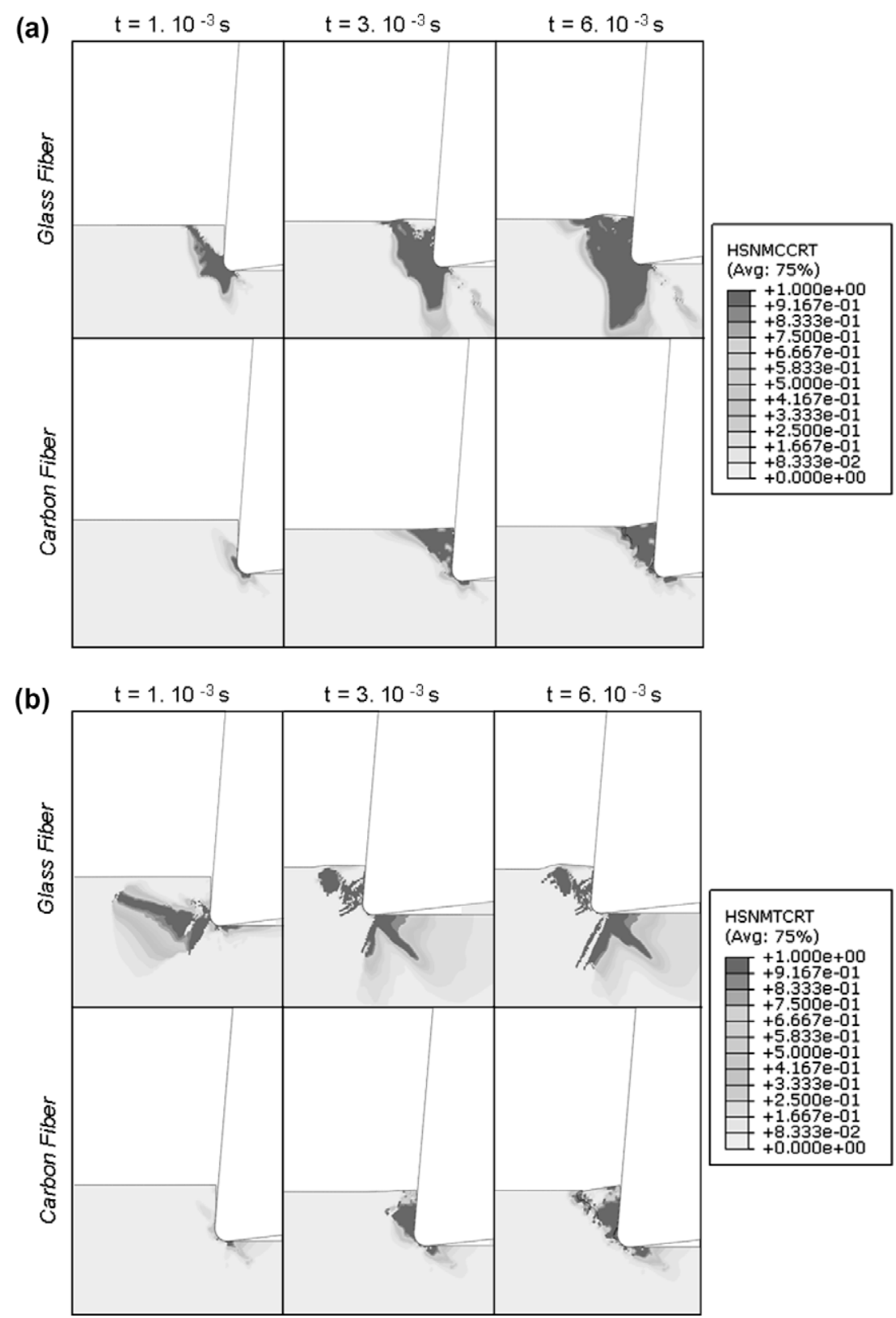

Fig. 6. Evolution of matrix damage (a) crushing and (b) cracking, during chip formation: comparison between CFRP and GFRP, fiber orientation $45^{\circ}$.

The differences observed between GFRPs and CFRPs could be related with the level of energy needed to complete breakage of the elements. GFRPs are classified as ductile composite materials exhibiting progressive failure under dynamic loads and also under machining operations. When the onset of damage is induced in an element it is deformed up to the level of energy allowed, thus GFRPs exhibited large strains. On the other hand CFRPs presents catastrophic failure with no progression of the damage, being catalogued as brittle composite materials. The elements do not suffer significant deformation, thus they break just after the damage onset restraining the damage extension on the workpiece [18].

The influence of fiber orientation on machining induced damage in the case of CFRPs is shown in Fig. 7, presenting matrix crushing and cracking damage corresponding to complete chip formation for the different orientations analyzed $\left(15^{\circ}, 30^{\circ}, 45^{\circ}, 60^{\circ}, 75^{\circ}, 90^{\circ}\right)$.

For orientation angle equal to $15^{\circ}$ it was observed the bending moment effect described in [22] as the cause of chip formation for brittle materials machined with positive rake angle tools. The interaction between tool and workpiece leaded to the formation of a stressed zone ahead the tip. When the stress state reached the level of damage initiation, a crack was formed in front of the cutting edge. Progression of the crack originated an almost rectangular chip acting as a cantilever, the fracture of the chip took place at the cantilever support. Cracking damage was observed along the primary zone (oriented parallel to fiber) while compressive damage occurred at the outer contour.

This bending effect was softened as the orientation angle was increased, due to the enhanced contribution of the fiber to strength in the direction normal to cutting speed direction. Thus the chip size diminished and evolved to triangular shape. For the larger values of orientation angle $\left(75^{\circ}\right.$ and $\left.90^{\circ}\right)$ most elements located above the primary shear zone were eroded. The uncut chip zone experienced high levels of stress, being very low the contribution of fiber (with orientation 75 and 90 respectively) to strength in cutting speed direction, and thus resulting in damaged elements and subsequent deletion. 
(a)

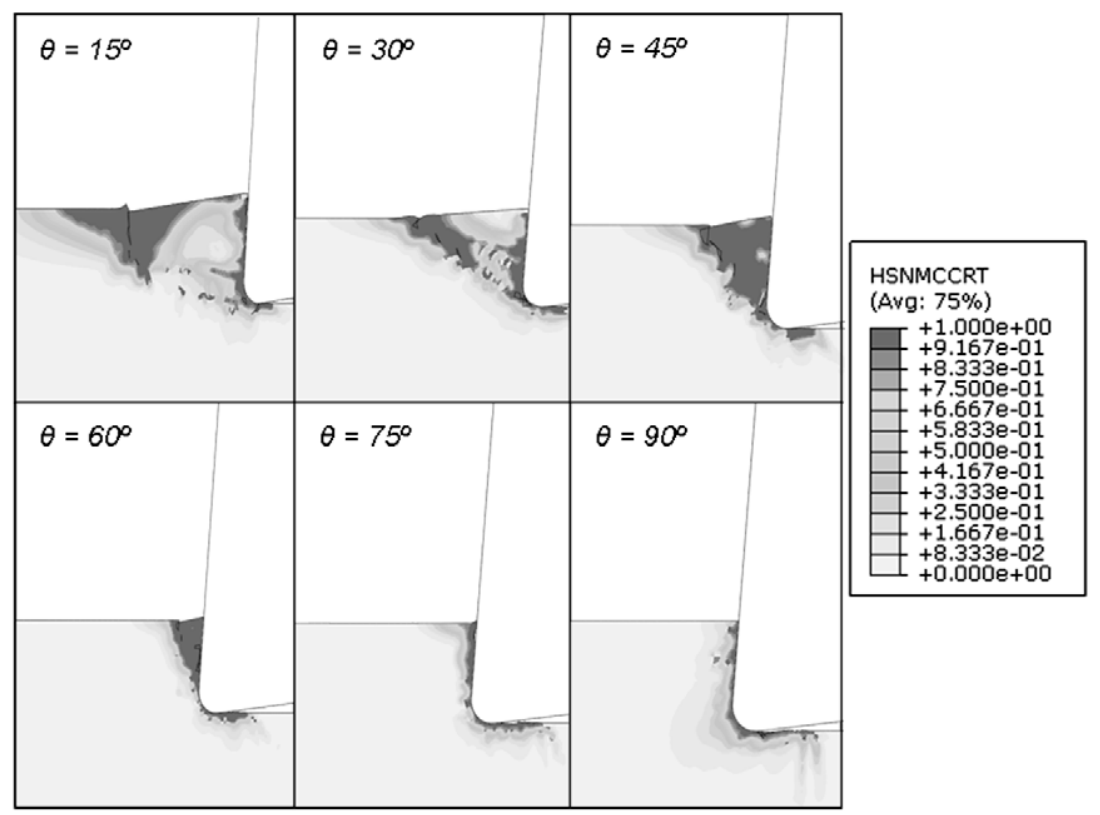

(b)

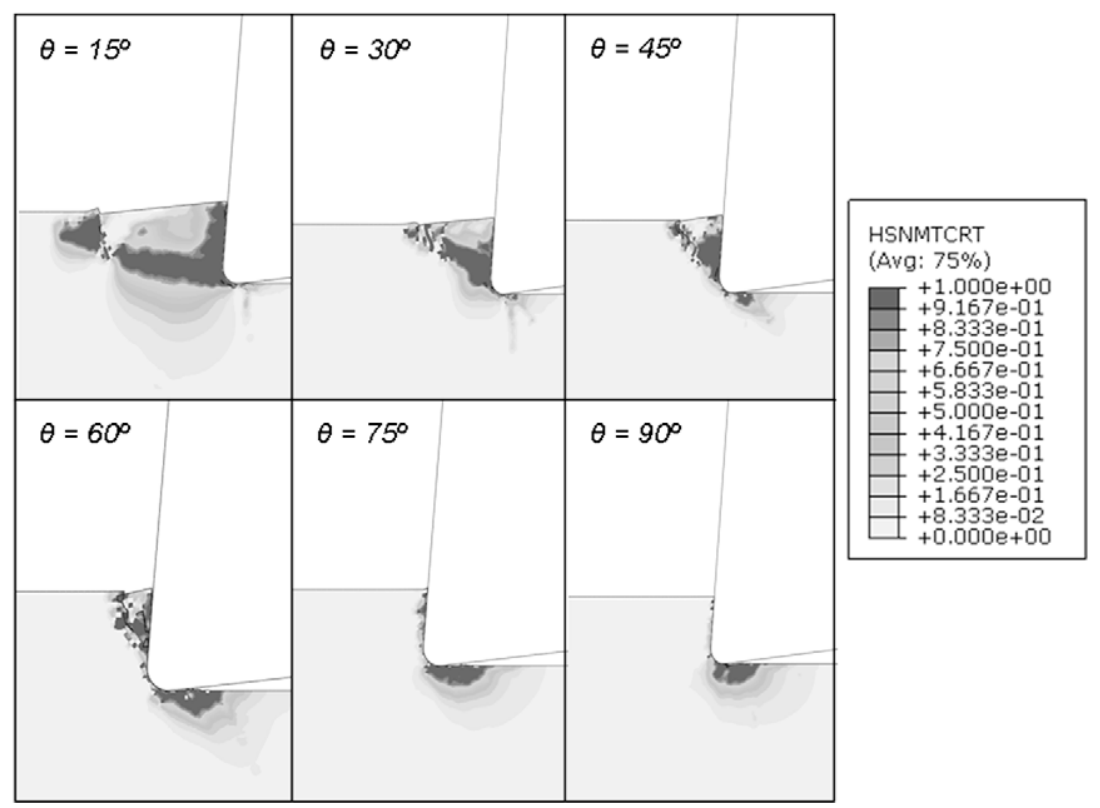

Fig. 7. Influence of fiber orientation on mechanisms of chip formation in orthogonal cutting of CFRPs. Contour of matrix damage crushing (a) and cracking (b).

While crushing damage was reduced with increased fiber angle, tensile subsurface damage was enhanced affecting larger zones under machined surface.

\subsection{Summary}

Main contributions of this paper obtained from described results are presented in this section and briefly summarized in Table 2:

(1) It is important to model initiation and complete formation of chip in order to obtain information of the machining process, such as stabilized cutting force and subsurface damage at machined surface. Explicit integration scheme used in simulations permitted to model efficiently a reasonably large cutting length, enough to reach steady state conditions.
Table 2

Summary of results obtained in the paper.

\begin{tabular}{|c|c|}
\hline & Numerical model of composites \\
\hline $\begin{array}{l}\text { Integration } \\
\text { scheme }\end{array}$ & $\begin{array}{l}\text { Explicit approach is used to simulate initiation and complete } \\
\text { formation of chip (see Figs. 1, } 4 \text { and 5) }\end{array}$ \\
\hline $\begin{array}{l}\text { Composite } \\
\text { behaviour }\end{array}$ & $\begin{array}{l}\text { The energy needed to complete breakage of the elements } \\
\text { characterize ductile or brittle behaviour (see Figs. } 3 \text { and 5) }\end{array}$ \\
\hline $\begin{array}{l}\text { Chip } \\
\text { formation }\end{array}$ & $\begin{array}{l}\text { Strongly dependent on composite behaviour and fiber } \\
\text { orientation (see Figs. 3, } 5 \text { and 7) }\end{array}$ \\
\hline Damage & $\begin{array}{l}\text { Both tensile and compressive matrix damage modes are } \\
\text { significant. Strongly dependent on composite behaviour and } \\
\text { fiber orientation (see Figs. } 2 \text { and } 6 \text { ) }\end{array}$ \\
\hline
\end{tabular}

(2) Concerning cutting operations, CFRPs is considered to be brittle composite material while GFRPs is catalogued as ductile composite material. Numerical parameter representing 
the degree of ductility exhibited by the composite during cutting is the energy needed to complete breakage of the elements. This fact is coherent with the behaviour observed when testing these two types of composite under dynamic loading [19].

(3) Both tensile and compressive matrix damage modes are significant and should be considered when analyzing composite orthogonal cutting.

(4) Machining induced subsurface damage experienced by CFRPs is much reduced than that observed in GFRPs. This behaviour could be related also with the energy absorbed up to element breakage. GFRPs exhibited large deformation before breakage and extended damage beneath and ahead the tool tip. However in the case of CFRPs the damage was located in the zone of uncut chip in front of the interface, being this zone removed with the chip formation.

(5) The chip formation mechanisms and induced damage strongly depends on fiber orientation. The effect of bending moment (involving both cracking and crushing damage) was observed for fiber orientations close to the cutting speed direction in CFRPs. The increment of angle orientation leaded to increased crushing damage beneath the machined surface.

\section{Conclusions}

Main contribution of this paper is the dynamic approach to model orthogonal cutting of both GFRP and CFRP and the analysis of machining induced damage. The model developed using ABAQUS/Explicit was validated with numerical and experimental results obtained for GFRPs from scientific literature. The material CFRPs was characterized from a previous prestigious work involving wide number of test conditions [18].

Both initiation and complete chip formation were simulated obtaining cutting force and subsurface damage. The energy needed to complete breakage of the elements characterize the composite behaviour (brittle/ductile) and strongly influenced the chip formation mechanisms and matrix damage, being both phenomena also dependent on fiber orientation. Machining induced subsurface damage was much reduced for brittle composite (CFRPs) than for ductile composite (GFRPs). This is a significant advantage of the CFRPs when compared with GFRPs, taking into account the high responsibility of the CFRPs structural components for aeronautical applications.

This work should be completed with analysis of influence of cutting parameters, tool geometry and numerical parameters of the model. However the most significant lack in this field is the few orthogonal cutting tests dealing with LFRPs available for validation of the models. Concerning the future work, it would be desirable to perform both numerical and experimental approaches to the problem of composite cutting.

\section{Acknowledgements}

The authors are indebted for the financial support of this work, to the Ministry of Science and Education of Spain (under Project DPI2008-06746). The authors also acknowledge to the CAMUC3 $M$ for the financial support obtained for this work with the Project CCG08-UC3 M/DPI-4494.

\section{References}

[1] Mkaddem A, El Mansori M. Finite element analysis when machining UGFreinforced PMCs plates chip formation crack propagation and induceddamage. J Mater Des 2009. doi:10.1016/j.matdes.2008.12.009.

[2] Nayak D, Bhatnagar N, Mahajan P. Machining studies of uni-directional glass fiber reinforced plastic (UD-GFRP) composites part 1: effect of geometrical and process parameters. Mach Sci Technol 2005;9:481-501.

[3] Bhatnagar N, Nayak D, Singh I, Chouhan H, Mahajan P. Determination of machining-induced damage characteristics of fiber reinforced plastic composite laminates. Mater Manuf Process 2004;19(6):1009-23.

[4] Wang XM, Zhang LC. An experimental investigation into the orthogonal cutting of unidirectional fiber reinforced plastics. Int $J$ Mach Tools Manuf 2003;43:1015-22.

[5] Miguélez H, Zaera R, Molinari A, Cheriguene R, Rusinek A. Residual stresses in orthogonal cutting of metals: the effect of thermomechanical coupling parameters and of friction. J Therm Stresses 2009;32:1-20.

[6] Mkaddem A, Demirci I, El Mansori M. A micro-macro combined approach using FEM for modelling of machining of FRP composites: cutting forces analysis. Compos Sci Technol 2008;68:3123-7.

[7] Nayak D, Bhatnagar N, Mahajan P. Machining studies of UD-FRP composites part 2: finite element analysis. Mach Sci Technol 2005;9:503-28.

[8] Venu Gopala Rao G, Mahajan P, Bhatnagar N. Micro-mechanical modelling of machining of FRP composites - cutting force analysis. Compos Sci Technol 2007;67:579-93.

[9] Arola D, Ramulu M. Orthogonal cutting of fiber-reinforced composites: a finite element analysis. Int J Mech Sci 1997;39:597-613.

[10] Ramesh MV, Seetharamu KN, Ganesan N, Shivkumar MS. Analysis of machining of FRPs using FEM. Int J Mach Tools Manu 1998;38:1531-49.

[11] Mahdi M, Zhang L. An adaptive three-dimensional finite element algorithm for the orthogonal cutting of composite materials. J Mater Process Technol 2001;113:368-72.

[12] Mahdi M, Zhang L. A finite element model for the orthogonal cutting of fiber reinforced composite materials. J Mater Process Technol 2001;113:368-72.

[13] Arola D, Sultan MB, Ramulu M. Finite element modelling of edge trimming fiber-reinforced plastics transactions of the ASME. J Eng Mater Technol 2002;124:32-41.

[14] Hibbit, Karlson, Sorensen Inc. ABAQUS user's manual 6.4-1; 2003.

[15] Miguélez H, Zaera R, Cheriguene R, Molinari A. Numerical analysis of the influence of cutting speed in machined induced residual stresses in aeroengine alloys, EDP Sciences, 2009. doi:10.1051/dymat/2009244.

[16] Hashin Z, Rotem A. A fatigue criterion for fiber-reinforced materials. J Compos Mater 1973;7:448-64.

[17] Hashin Z. Failure criteria for unidirectional fiber composites. J Appl Mech 1980;47:329-34.

[18] Rotem A. Residual flexural strength of FRP composite specimens subjected to transverse impact loading. SAMPE J 1988;24:19-25.

[19] Soden, Hinton, Kaddour. Lamina properties, lay-up configurations and Loading conditions for a range of fiber-reinforced composite laminates. Compos Sci Technol 1998;58:1011-22.

[20] Hinton, Soden. Predicting failure in composite laminates: the background to the exercise. Compos Sci Technol 1998;58(7):1001-10.

[21] Lasri L, Nouari M, El Mansori M. Modelling of chip separation in machining unidireccional FRP composites by stiffness degradation concept. Compos Sci Technol 2009;69:684-92.

[22] Astakhov V. Metal cutting mechanics. CRC Press; 1999. 